Article

\title{
Protective Effects of Bacteriophages against Aeromonas hydrophila Causing Motile Aeromonas Septicemia (MAS) in Striped Catfish
}

\author{
Tuan Son Le ${ }^{1,2}$, Thi Hien Nguyen ${ }^{3}$, Hong Phuong Vo ${ }^{3}$, Van Cuong Doan ${ }^{3}$, Hong Loc Nguyen ${ }^{3}$, \\ Minh Trung Tran ${ }^{3}$, Trong Tuan Tran ${ }^{3}$, Paul C. Southgate ${ }^{4}$ and D. İpek Kurtböke ${ }^{1, *(1)}$ \\ 1 GeneCology Research Centre, Faculty of Science, Health, Education and Engineering, University of the \\ Sunshine Coast, 90 Sippy Downs Drive, Sippy Downs, QLD 4556, Australia; tuan.son.le@research.usc.edu.au \\ 2 Research Institute for Marine Fisheries, 224 Le Lai, Ngo Quyen, Hai Phong 180000, Vietnam \\ 3 Research Institute for Aquaculture No. 2, 116 Nguyen Dinh Chieu, District 1, Ho Chi Minh 700000, Vietnam; \\ nguyenhien05@gmail.com (T.H.N.); vohongphuong@gmail.com (H.P.V.); \\ vancuongdisaqua@gmail.com (V.C.D.); hongloc@gmail.com (H.L.N.); trung16893@yahoo.com.vn (M.T.T.); \\ tuantran_695@yahoo.com.vn (T.T.T.) \\ 4 Australian Centre for Pacific Islands Research and Faculty of Science, Health, Education and Engineering, \\ University of the Sunshine Coast, Maroochydore, QLD 4556, Australia; psouthgate@usc.edu.au \\ * Correspondence: ikurtbok@usc.edu.au; Tel: +61-07-5430-2819
}

Received: 28 December 2017; Accepted: 23 February 2018; Published: 25 February 2018

\begin{abstract}
To determine the effectivity of bacteriophages in controlling the mass mortality of striped catfish (Pangasianodon hypophthalmus) due to infections caused by Aeromonas spp. in Vietnamese fish farms, bacteriophages against pathogenic Aeromonas hydrophila were isolated. A. hydrophila-phage 2 and A. hydrophila-phage 5 were successfully isolated from water samples from the Saigon River of Ho Chi Minh City, Vietnam. These phages, belonging to the Myoviridae family, were found to have broad activity spectra, even against the tested multiple-antibiotic-resistant Aeromonas isolates. The latent periods and burst size of phage 2 were $10 \mathrm{~min}$ and 213 PFU per infected host cell, respectively. The bacteriophages proved to be effective in inhibiting the growth of the Aeromonas spp. under laboratory conditions. Phage treatments applied to the pathogenic strains during infestation of catfish resulted in a significant improvement in the survival rates of the tested fishes, with up to $100 \%$ survival with MOI 100, compared to $18.3 \%$ survival observed in control experiments. These findings illustrate the potential for using phages as an effective bio-treatment method to control Motile Aeromonas Septicemia (MAS) in fish farms. This study provides further evidence towards the use of bacteriophages to effectively control disease in aquaculture operations.
\end{abstract}

Keywords: Aeromonas hydrophila; Motile Aeromonas Septicemia; MAS; multiple-antibiotic-resistance; bacteriophage; biological control; striped catfish (Pangasianodon hypophthalmus)

\section{Introduction}

Striped catfish (Pangasianodon hypophthalmus) is one of the most important farmed fish species, especially in Vietnam, Thailand, Cambodia, Laos and, more recently, the Philippines and Indonesia [1]. Vietnam supplied $90 \%$ of catfish production with a value of US\$1.1 to 1.7 billion in 2015. Motile Aeromonas Septicemia (MAS), also called haemorrhage disease or red spot disease, causes great losses for farmers (up to $80 \%$ mortality) and presents in fish with clinical signs of haemorrhages on the head, mouth, and at the base of fins, a red, swollen vent, and the presence of pink to yellow ascitic fluid [2]. Aeromonas hydrophila, Aeromonas caviae, and Aeromonas sobria species were often isolated from diseased catfish, and new species such as Aeromonas dhakensis and Aeromonas veronii were also reported by using molecular methods based on the sequencing of the $r p o \mathrm{D}$ gene [3]. 
Multiple antibiotic resistance (MAR) of A. hydrophila strains has been reported in different countries. Vivekanandhan et al. [4] tested 319 strains of $A$. hydrophila isolated from fish and prawns in South India and indicated that all of them were resistant to methicillin, rifampicin, bacitracin, and novobiocin (99\%). Moreover, 21 Aeromonas spp. isolated from carp showed resistance to ampicillin and penicillin [5]. Recently, Thi et al. [6] tested antibiotic resistance of 30 strains of $A$. hydrophila isolated from diseased striped catfish in the Mekong Delta from January 2013 to March 2014. The study found that $A$. hydrophila isolates were highly resistant to tetracycline and florfenicol and were completely resistant to trimethoprim, sulfamethoxazole, ampicillin, amoxicillin, and cefalexine.

ALPHA JECT ${ }^{\circledR}$ Panga 2 vaccine, protecting against Edwardsiella ictaluri and A. hydrophila, has been approved for market in Vietnam since the early 2017 (https:/ / www.pharmaq.no/updates/pharmaqfish-va/). However, the cost-effectiveness of vaccine use in catfish production is another obstacle in intensive catfish production. Moreover, the development of a commercial vaccine against $A$. hydrophila has been slow because A. hydrophia is biochemically and serologically heterogeneous [7]. Therefore, there is a need for effective, environmentally safe control measures for managing MAS in catfish.

One approach has been the use of bacteriophages (phages) to control pathogenic bacteria in aquaculture operations. Recently, studies related to the use of phages specific to A. hydrophila in aquaculture have gained attention. Hsu et al. [8] isolated two A. hydrophila phages and three Edwardsiella tarda phages to treat disease in eels (Anguilla japonica) in vitro. The phages reduced bacterial density by about 1000 times after $2 \mathrm{~h}$ when the MOI was 11.5 at $25{ }^{\circ} \mathrm{C}$ in the fluid environment. El-Araby et al. [9] demonstrated the effectiveness of bacteriophage $\mathrm{ZH} 1$ and $\mathrm{ZH} 2$ treatment against $A$. hydrophila in Tilapia, improving the survival rates by up to $82 \%$.

However, so far, treatments using bacteriophages against pathogens causing MAS in catfish have not been studied extensively. The objective of this study was, therefore, to isolate bacteriophages infective in pathogenic $A$. hydrophila with a long-term objective to eradicate this disease-causing pathogen in aquaculture operations.

\section{Results}

\subsection{Prophage Induction}

No reduction in the optical density of bacterial suspension treated with Mitomycin C (Table S1, Supplementary Materials) and no clear zones from the spot technique were observed. Therefore, it was concluded that there was no prophage in A. hydrophila N17.

\subsection{Antibiotic Susceptibility}

All isolates were completely $(100 \%)$ resistant to oxytetracycline, ampicillin, gentamycin and amoxicillin/clavulanic acid, enrofloxacin, and bactrim. Nearly all isolates (83.3\%) were resistant to kanamycin and 33.3\% were resistant to tetracycline, doxycycline, and ciprofloxacin (Table 1).

Table 1. Antibiogram profile of the Aeromonas hydrophila strains tested.

\begin{tabular}{cc}
\hline Antibiotics & Number of Resistant Isolates $(\boldsymbol{n}=\mathbf{6})$ \\
\hline Tetracycline & 2 \\
Oxytetracycline & 6 \\
Gentamycin & 6 \\
Kanamycin & 5 \\
Bactrim (SMX/TMP) & 6 \\
Doxycycline & 2 \\
Enrofloxacin & 6 \\
Amoxicillin/clavulanic acid & 6 \\
Ampicillin & 6 \\
Ciprofloxacin & 2 \\
\hline
\end{tabular}




\subsection{Isolation and Characterization of Bacteriophages}

The A. hydrophila-phage 2 (or $\Phi 2$ ) and A. hydrophila-phage 5 (or $\Phi 5$ ) were successfully isolated against the propagation hosts used (Figure 1 and Table 2).

$\Phi 2 \mathrm{had}$ an isometric head of $129 \mathrm{~nm}$ in diameter with a tail sheath $173 \mathrm{~nm}$ long and $15 \mathrm{~nm}$ wide. $\Phi 5$ was composed of: (i) an isometric head of $120 \mathrm{~nm}$ in diameter, (ii) a tail sheath of $198 \mathrm{~nm}$ in length and $15 \mathrm{~nm}$ in width. All of the phages had contractile tails (Figure 1 and Table 2).

Table 2. Characteristics of bacteriophages against A. hydrophila strains.

\begin{tabular}{ccccccccc}
\hline \multirow{2}{*}{$\boldsymbol{\Phi}$} & $\begin{array}{c}\text { Concentration } \\
\text { PFU/mL }\end{array}$ & \multicolumn{2}{c}{ Head (nm) } & \multicolumn{2}{c}{ Neck (nm) } & \multicolumn{2}{c}{ Tail Sheath (nm) } & \multirow{2}{*}{ Genus } \\
\cline { 3 - 7 } & & $\mathbf{L}$ & $\mathbf{W}$ & $\mathbf{L}$ & $\mathbf{W}$ & $\mathbf{L}$ & $\mathbf{W}$ & \\
\hline 2 & $10^{9}$ & & 129 & 10 & 15 & 173 & 15 & Spounalikevirus \\
5 & $10^{10}$ & & 120 & 15 & 15 & 198 & 15 & Spounalikevirus \\
\hline
\end{tabular}

W: width; L: length.

Both phages produced clear plaques with diameters of $0.1 \mathrm{~mm}$ (Figure 1).



(a)

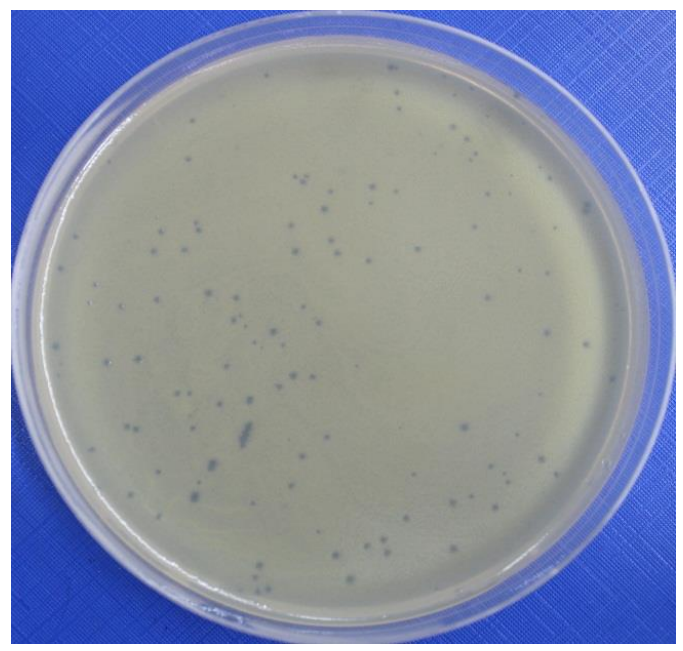

(c)

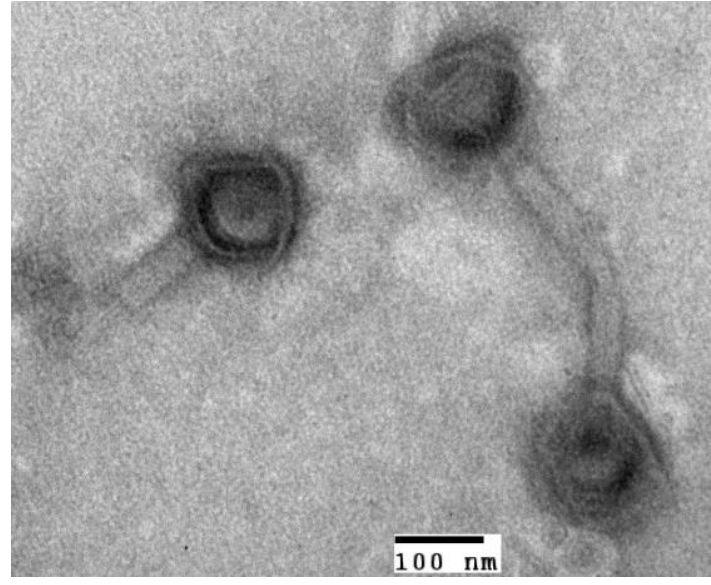

(b)

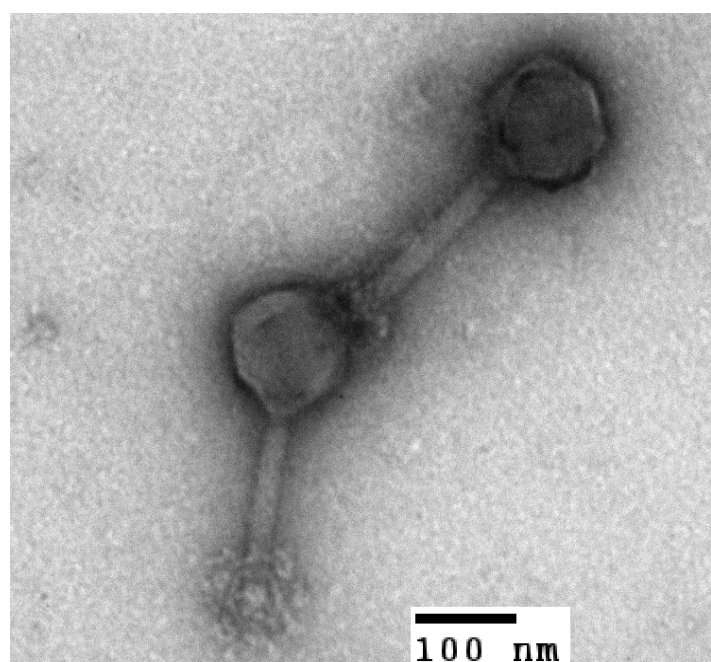

(d)

Figure 1. Plaque formation and microphotograph of $A$. hydrophila phages. (a,b) $\Phi 2$ and (c,d) phage $\Phi 5$.

The genome size of the phage isolates was above $20 \mathrm{~kb}$. The genomic material of the isolated phages was not digested by Mung bean nuclease and RNase A. Since Mung bean nuclease specifically 
cuts single-stranded nucleic acids of both DNA and RNA, it was concluded that the genomic DNA of both phages was double-stranded. RNA nucleic acids are degraded by RNase A, therefore, the nucleic acids of $\Phi 2$ and $\Phi 5$ were determined as double-stranded DNA (dsDNA) (Figure 2). The phages $\Phi 2$ and $\Phi 5$ belong to the Myoviridae family.

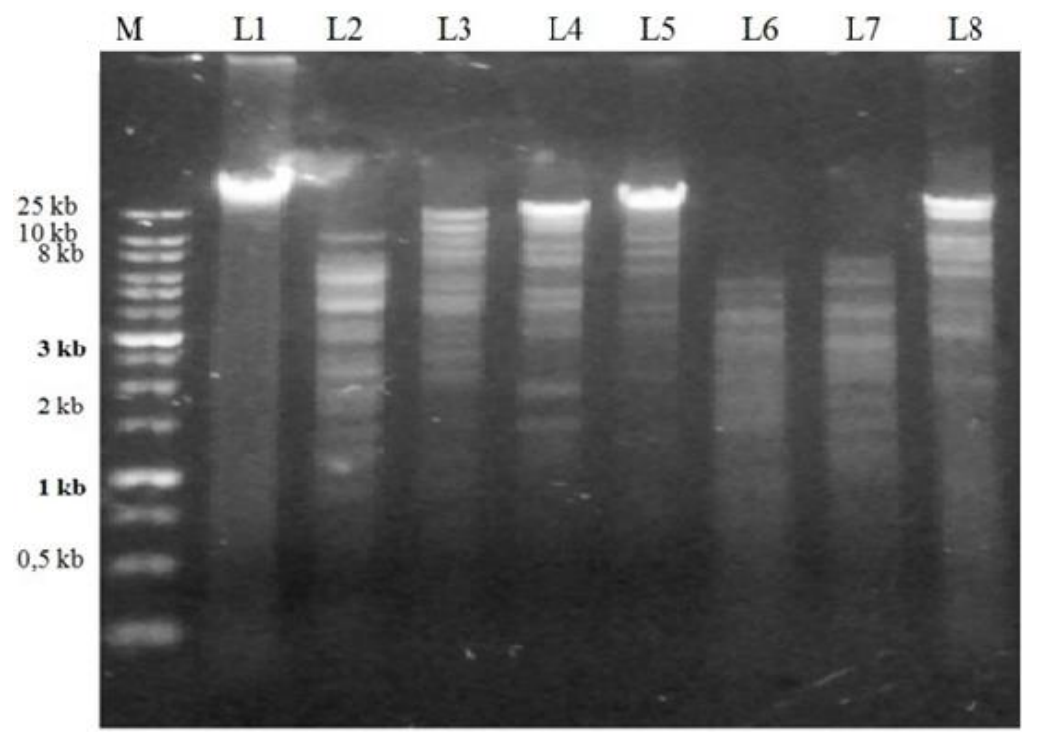

Figure 2. Restriction enzyme-digested fragments of the genomic DNA of A. hydrophila-phage 2. Footnote: Lane M: 1kb Plus Opti-DNA Marker (ABM, Canada); Lane L1: genomic DNA of $\Phi 2$; Lanes L2-L8: genomic DNA of $\Phi 2$ digested with EcoRV; EcoRI; Ncol; SalI; MspI; XmnI; KpnI, restriction enzymes respectively.

\subsection{Host Range}

Phage 2 and phage 5 were found to inhibit the growth of all $A$. hydrophila strains tested. None of the other 27 species was found to be susceptible to these phages (Table S2, Supplementary Materials).

\subsection{Adsorption Rate of Phages and One-Step Growth Curve}

The number of free phages in suspension decreased over time, as illustrated in the adsorption curve (Figure 3a). At $40 \mathrm{~min}$, the percentage of $\Phi 2$-infected bacteria was over $90 \%$.

The one-step growth experiment (Figure $3 b$ ) results revealed that the latent period and burst size of $\Phi 2$ were 10 and 213 PFU per infected host cell, respectively.

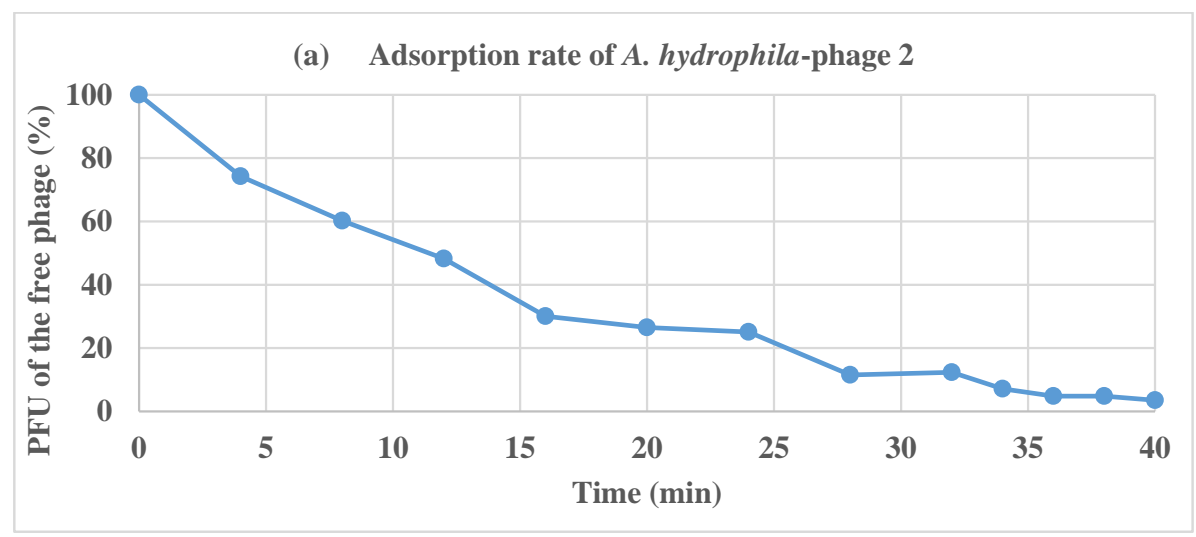

Figure 3. Cont. 


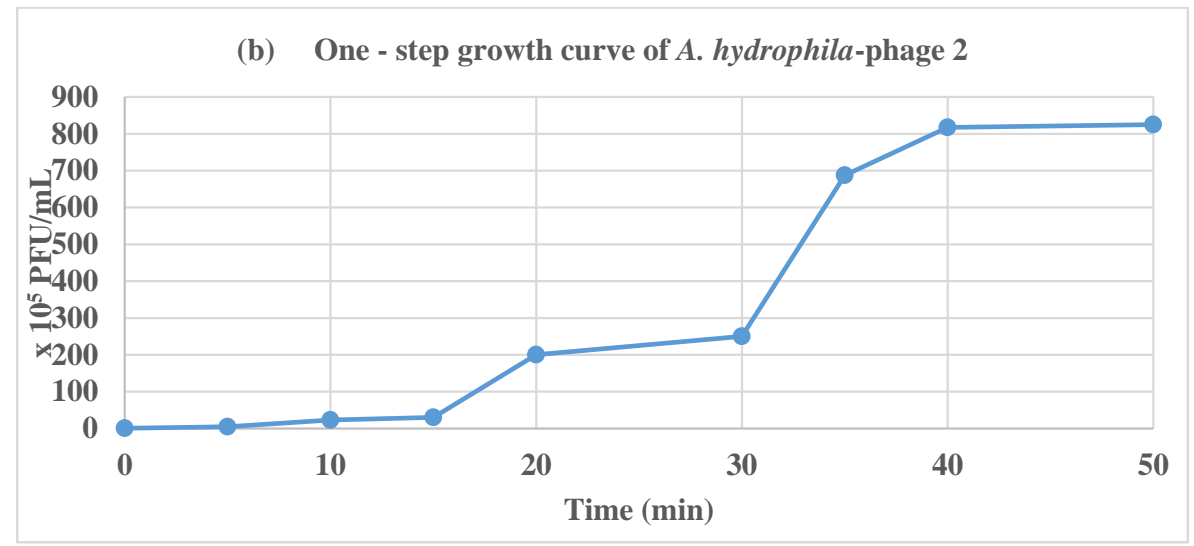

Figure 3. (a) Adsorption rate and (b) one-step growth curves of $\Phi 2$.

\subsection{Inactivation of Aeromonas Species in Vitro}

The bacterial concentration $\left(\mathrm{OD}_{550 \mathrm{~nm}}\right.$ values) of the uninfected control (only A. hydrophila N17) increased continuously during $18 \mathrm{~h}$ of incubation. In contrast, during the infection with $\Phi 2$ at MOI 1 , MOI 0.1, and MOI 0.01 bacterial growth began to be inhibited at 1, 2, and $2.5 \mathrm{~h}$, respectively, and the inhibition was maintained up to $8 \mathrm{~h}$ (Figure 4a). Then, the bacterial concentration increased as a consequence of the development of phage-resistant $A$. hydrophila cells.

The lowest $\mathrm{OD}_{550 \mathrm{~nm}}$ value was $0.177 \pm 0.023$ after $4 \mathrm{~h}$ of incubation of $\Phi 5$ at MOI 0.1. There was a significant decline in the bacterial concentration (MOI 0.01, 0.1, and 1 ) in the first $3 \mathrm{~h}$, followed by low level stabilization in the next 1,2 , and $4 \mathrm{~h}$ for MOI 1, 0.1, and 0.01 , respectively (Figure $4 \mathrm{~b}$ ). Then, the bacterial concentration underwent a turnaround because of the development of phage-resistant A. hydrophila cells.

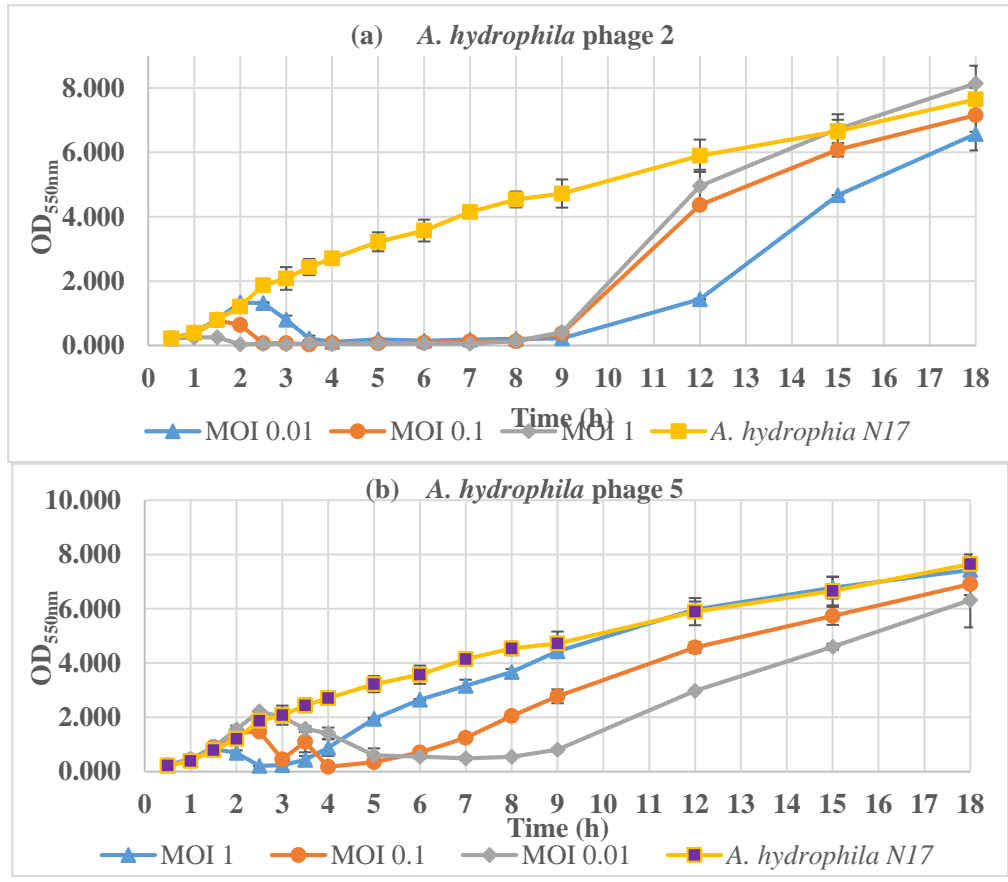

Figure 4. Inactivation of $A$. hydrophila N17 by the phages (a) $\Phi 2$ and (b) $\Phi 5$ at different MOI $(0.01,0.1$ and 1). 


\subsection{Phage Treatment of Infected Fish}

The negative control 1 (fishes with no injection) and negative control 2 (fishes injected with the growth medium filtered to remove bacterial cells) showed no mortality of catfish (Figure 5), indicating that the uninfected, control medium did not have any detrimental effect on fish health.

Catfish in the positive control groups (infected with A. hydrophila N17) that were not treated with bacteriophages started to die at a constant rate starting from post-infection day two, with a cumulative mortality rate of $81.67 \pm 2.36 \%$ (Figure 5 ).

In contrast, the fish treated with the phages showed lower mortality rates at each different MOI $(p<0.01)$. While no mortality was observed in the groups treated with MOI 100, the cumulative mortalities in the other groups were $45 \%$ (MOI 1) and $68.33 \pm 2.36 \%$ (MOI 0.01) at the end of the eight-day experiment (Figure 5).

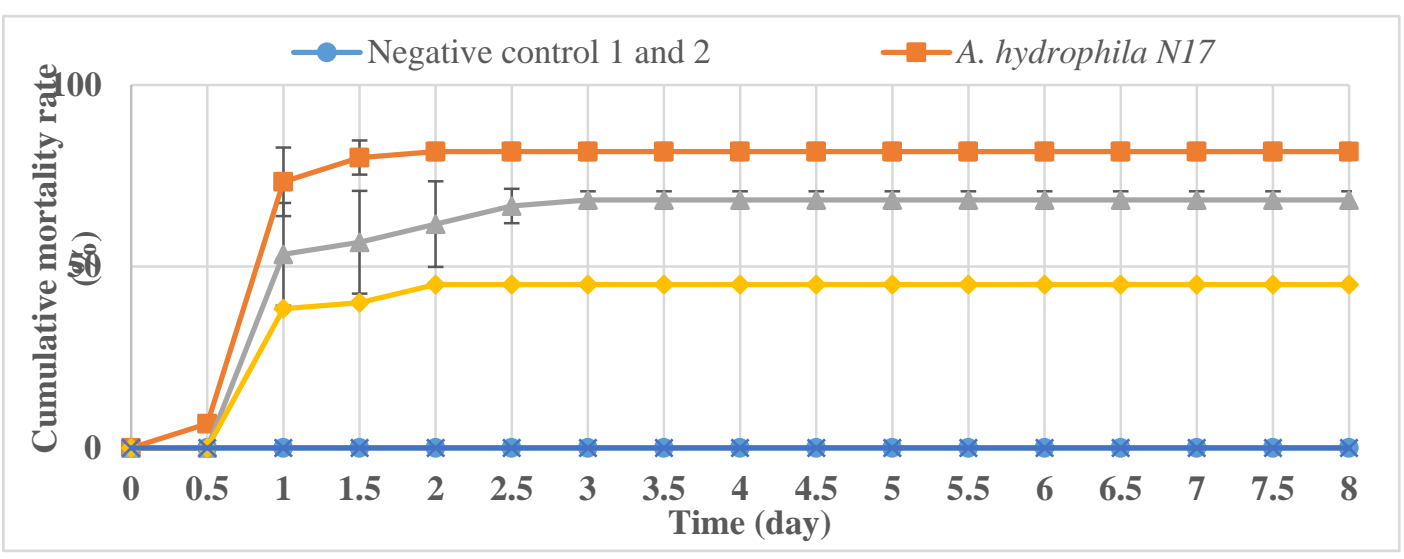

Figure 5. Cumulative mortality rates (\%) of striped catfishes obtained in challenging experiments using A. hydrophia N17 and the phage cocktail at the different MOIs $(0.01,0.1$, and 1). The ratio of $\Phi 2$ to $\Phi 5$ in a phage cocktail was 1:1.

\section{Discussion}

The findings of this study demonstrate that the examined Aeromonas spp. were resistant to multiple antibiotics and were thus able to cause high mortality rates in catfish in Vietnam, in spite of the use of various antibiotic treatments. In the bacteriophage treatments, however, $\Phi 2$ and $\Phi 5$ were able to lyse all tested $A$. hydrophila strains, displaying strong inhibition also of the virulent A. hydrophila strains carrying many virulence genes. Therefore, $\Phi 2$ and $\Phi 5$ are promising candidates for the application of a phage therapy to control Aeromonas infection in catfish.

Phage $\Phi 2$ and $\Phi 5$ were found to belong to the Myoviridae family, and our findings are in line with those of Ackermann [10] who indicated that 33 of a total of 43 Aeromonas phages he investigated were tailed and belonged to the Myoviridae family. Recently, other Aeromonas phage studies against different Aeromonas species by Haq et al. [11], Jun et al. [12], and Kim et al. [13] also reported that all phages they identified belonged to the Myoviridae family. Therefore, Myoviridae family members are most likely to be abundant in natural environments.

There was a correlation between the diameter of the plaques observed and the latent period and burst size for the A. hydrophila phage. The $\Phi 2$ had a short latent period $(10 \mathrm{~min})$, and these findings are in line with another study conducted by Anand et al. [14] who found that Aeromonas phage BPA 6 had a latent period of $10 \mathrm{~min}$ and a burst size of $244 \mathrm{PFU} /$ cell.

The different MOI of $\Phi 2$ and $\Phi 5$ caused different bacterial growth patterns. The higher the MOI value, the sooner phage-resistant bacterial cells appeared. A similar result was noted by Kim et al. [13] for the phage PAS 1 against an Aeromonas salmonicida strain, indicating that bacterial resistance appeared after 3,6 , and $24 \mathrm{~h}$ at MOIs 10,1 , and 0.1 , respectively. 
Several Aeromonas phages, such as Aeh1, Aeh2, AH1 have also been reported [12,15,16]. However, there have been few reports demonstrating the successful use of phages for the treatment of Aeromonas infections in catfish. The treatment of catfish by an intraperitoneal (IP) injection illustrated significant protective effects, which increased the relative percentages of the survival rates observed for fish compared to the controls when the MOI increased. Our study revealed that in the MOI-100 experiment the relative percentage survival was $100 \%$. The study of Jun et al. [12] showed that the relative percentage survival of fish treated with $A$. hydrophila phages pAh6-C and pAh1-C was $16.67 \pm 3.82 \%$ and $43.33 \pm 2.89 \%$, respectively, when the fish were injected with the bacterium $\left(2.6 \times 10^{7} \mathrm{CFU} /\right.$ fish $)$. However, the labour-intensive and time-consuming mode of delivery of bacteriophages can constitute a disadvantage for the treatment of fish by IP injection in catfish farms. Therefore, further studies should be conducted into whether phage treatments are effective when an on-farm oral method of administration is evaluated. With the use of bioreactors, large volumes of bacteriophages can be produced for bacteriophage incorporation into fish feed. Moreover, the survival of phages and their persistent survival on or in fish, as well as in phage-coated feed preparations should be studied under different environmental factors (e.g., temperature, salt concentration) to determine whether phages are able to persist and effectively reduce Aeromonas spp. levels in fish farms. In conclusion, this study demonstrates that phage treatment of Aeromonas spp. might be an effective tool to improve the survival of farmed catfish affected by MAS.

\section{Materials and Methods}

\subsection{Aeromonas Species}

Bacterial isolates stored at the Research Institute for Aquaculture No. 2 (Ho Chi Minh City, Vietnam) and the ATCC type strains of the pathogens are listed in Table S2. Isolates were previously obtained from diseased catfish in farms in the south of Vietnam (Table S2).

\subsection{Prophage Induction}

In order to choose an Aeromonas species as a propagation host for phage isolation, A. hydrophila N17 was subjected to a prophage induction test. The Aeromonas species was cultured in $10 \mathrm{~mL}$ fresh Luria-Bertani (or LB) broth (Sigma-Aldrich, St. Louis, MO, USA) and incubated at $30^{\circ} \mathrm{C}$ on an orbital shaker operating at $150 \mathrm{rpm}$ until reaching an $\mathrm{OD}_{550 \mathrm{~nm}}$ of 0.2. Mitomycin C (Sigma-Aldrich) was added to a final concentration of $1 \mu \mathrm{g} / \mathrm{mL}$ and $5 \mu \mathrm{g} / \mathrm{mL}$, and again the bacterial suspension was incubated at $30^{\circ} \mathrm{C}$ on an orbital shaker operating at $150 \mathrm{rpm}$. The cell density of the bacteria $\left(\mathrm{OD}_{550 \mathrm{~nm}}\right)$ was monitored every $1 \mathrm{~h}$ for a $6 \mathrm{~h}$ period. At the end of the incubation, the bacterial suspension was centrifuged at 10,000 $\mathrm{g}$ for $15 \mathrm{~min}$ and filtered through a nitrocellulose filter $(0.45 \mu \mathrm{m}$, Merck Millipore, Burlington, MA, USA) before spotting the filtrate onto an agar plate seeded with the host bacterium to confirm the presence of viable phage particles. A significant decrease in the cell density $\left(\mathrm{OD}_{550 \mathrm{~nm}}\right)$ suggested that prophages were released $[17,18]$.

\subsection{Antibiotic Susceptibility}

Antibiotic susceptibility tests of six A. hydrophila strains [3] were conducted against 10 different antimicrobial susceptibility discs (OXOID, Hampshire, UK) by the method recommended by the Clinical and Laboratory Standards Institute [19]. The antimicrobial agents tested included tetracycline $(30 \mu \mathrm{g})$, doxycycline $(30 \mu \mathrm{g})$, oxytetracycline $(30 \mu \mathrm{g})$, bactrim (SMX/TMP) $(23.75 / 1.25 \mu \mathrm{g})$, gentamycin $(40 \mu \mathrm{g})$, kanamycin $(30 \mu \mathrm{g})$, ciprofloxacin $(10 \mu \mathrm{g})$, enrofloxacin $(10 \mu \mathrm{g})$, ampicillin $(33 \mu \mathrm{g})$, and amoxicillin-clavulanic acid $(20 / 10 \mu \mathrm{g})$.

The antimicrobial susceptibility of Aeromonas species is usually recorded using Enterobacteriaceae breakpoints [20]. Susceptible (S), intermediate resistance (I), and resistant (R) were evaluated according the criteria given in the Performance Standards for Antimicrobial Susceptibility Testing M100-S21 
(2017, Table 2A-1, pages 33-39) [19]. Multi-antibiotic resistance (MAR) was recorded when the bacteria resisted to three or more antibiotics [21].

\subsection{Isolation and Characterization of Bacteriophages}

Phages were isolated from water samples from the Saigon River in the south of Vietnam against A. hydrophila N17 and they were purified following the methods described by Jun et al. [12].

Phage titres were determined using both surface spread [22,23] and double-layer [24] agar plaque assay techniques where agar plates were previously seeded with the Aeromonas sp. $\left(\times 10^{6} \mathrm{CFU} / \mathrm{mL}\right)$.

For transmission electron microscopy (TEM): A 200 mesh copper grid was immersed in $40 \mu \mathrm{L}$ of phage solution for five min before fixing the phage with glutaraldehyde solution (1\%) for five $\mathrm{min}$. Then, the phage samples were negatively stained with $5 \%(w / v)$ uranyl acetate and observed by TEM (JEOL JEM-1010) operating at a voltage of $80 \mathrm{kV}$ at the Vietnam National Institute of Hygiene and Epidemiology. The phage morphology was determined using the criteria of the International Committee on Taxonomy of Viruses (ICTV) (http:/ / www.ictvonline.org/) and Ackermann et al. [25].

Phage genomic DNA extraction and restriction analyses: Phage genomic DNA was extracted using the Phage DNA Isolation Kit (Norgen Biotek Corp, Thorold, Canada). The nature of the nucleic acids was determined by digestion with Mung bean nuclease and RNase A (ThermoFisher Scientific, Waltham, MA, USA) as per the manufacturer's protocols. The genomic DNA phages were digested using the restriction enzymes: EcoRV, EcoRI, Ncol, SalI, MspI, XmnI, and KpnI, as per the manufacturer's instruction (ThermoFisher Scientific). The DNA fragments were then electrophoresed at $120 \mathrm{~V}$ for $40 \mathrm{~min}$.

\subsection{Host Range}

The method was adapted from Le et al. [23] and Goodridge et al. [26] with some modifications described below. The Aeromonas spp. (Table S2) were incubated overnight. Then, a $100 \mu \mathrm{L}$ aliquot of each Aeromonas spp. culture (optical density of 0.5 at $550 \mathrm{~nm}$ ) was spread on brain heart infusion agar (BHIA) (OXOID, UK) and dried for $20 \mathrm{~min}$ in a biological safety cabinet Class II. The host range of the phage was determined by pipetting $10 \mu \mathrm{L}$ of phage preparation $\left(\sim 10^{8} \mathrm{PFU} / \mathrm{mL}\right)$ on lawn cultures of the strains. The plates were observed for the appearance of clear zones after incubation at $30^{\circ} \mathrm{C}$ after $18 \mathrm{~h}$.

\subsection{Adsorption Rate of Phages}

Phage adsorption was studied using the method described previously [27]. A phage solution was added to $100 \mathrm{~mL}$ of log-phase growing Aeromonas hydrophila N17 culture $\left(\times 10^{7} \mathrm{CFU} / \mathrm{mL}\right)$ in LB broth to get a final MOI of 0.1. The mixture was incubated at $30^{\circ} \mathrm{C}$. An aliquot of $1 \mathrm{~mL}$ was collected from the sample every two min over a period of $60 \mathrm{~min}$. The sample was then centrifuged at $4000 \mathrm{~g}$ for $15 \mathrm{~min}$, and then the supernatant was diluted with SM buffer $+1 \%$ chloroform (http:/ / cshprotocols.cshlp.org/ content/2006/1/pdb.rec8111.full?text_only=true). Then, the titers of unabsorbed free phages in the supernatant were determined by the double-layer agar technique, and the results were recorded as percentages of the initial phage counts. The percentages of free phages and the adsorption rates were calculated following the formula of Haq et al. [11].

\subsection{One-Step Growth Curve}

The phage and bacteria were prepared in the same way as in the adsorption method described above. At $40 \mathrm{~min}$, when the adsorption rate was maximal, the mixture was further incubated at $30{ }^{\circ} \mathrm{C}$ with $150 \mathrm{rpm}$. Samples were collected every $5 \mathrm{~min}$ for $120 \mathrm{~min}$ and phage titers were determined by the double-layer agar technique. Then, the latent period and burst size were calculated [28]. 


\subsection{Inactivation of Aeromonas hydrophila N17 in Vitro}

The method used in this study was adapted from Jun et al. [12] and Le et al. [23] with some modifications described below. A. hydrophila N17 was streaked onto sheep blood agar (OXOID, UK), incubated at $30{ }^{\circ} \mathrm{C}$ overnight, and harvested on LB to have a final concentration of $10^{7} \mathrm{CFU} / \mathrm{mL}$. A $10 \mathrm{~mL}$ suspension of the Aeromonas sp. in LB (around $10^{7} \mathrm{CFU} / \mathrm{mL}$ ) was then mixed with same volume of a phage preparation (concentration of $10^{5}$ to $10^{7} \mathrm{PFU} / \mathrm{mL}$ ) to reach multiplicity of infection (MOI) of 0.01, 0.1, 1 (http:/ / www.bio-protocol.org/e1295). A $20 \mathrm{~mL}$ sample of Aeromonas sp. in LB $\left(\sim \times 10^{7} \mathrm{CFU} / \mathrm{mL}\right)$ was used as a control. The mixture was incubated at $30^{\circ} \mathrm{C}$ and $150 \mathrm{rpm}$. Samples were taken every $30 \mathrm{~min}$ for $8 \mathrm{~h}$ to determine the exact time of the appearance of phage-resistant bacteria, and every $60 \mathrm{~min}$ for the next $6 \mathrm{~h}$ to determine the increase in the concentration of phage-resistant bacteria. Then, samples were withdrawn every $3 \mathrm{~h}$ to the end of the experiment. The concentration of the Aeromonas sp. was measured by optical density determination at $550 \mathrm{~nm}$ using a spectrophotometer (Thermo Scientific Genesys 20, Waltham, MA, USA).

\subsection{Phage Treatment of Infected Fish}

A total of 360 healthy catfish (Pangasianodon hypophthalmus) (30 g/fish) were divided into 12 groups in $50 \mathrm{~L}$ plastic tanks at $30 \pm 1{ }^{\circ} \mathrm{C}$. All treatment fishes were infected intraperitoneally with A. hydrophila N17 (final concentration: $3.2 \times 10^{6} \mathrm{CFU} /$ fish) and were then immediately injected with a phage cocktail (MOI 0.01, 1 and 100). A positive control was composed of fishes injected with A. hydrophila N17 only. Negative controls 1 and 2 were fishes with no injection and fishes injected with fluid separated from the broth containing bacteria and medium, respectively. The mixed phage preparation consisted of $\Phi 2$ and $\Phi 5$.

The mortality rates of the fishes were recorded every $12 \mathrm{~h}$ for eight days, and the kidneys of both the dead and surviving fishes were subjected to a bacterial isolation study [3]. Bacteria isolation was carried out from all dead fishes, indicating that the deaths were caused by A. hydrophila [3]. All treatments were performed in duplicates.

The animal experiment was conducted according to the animal ethical guidelines of the Vietnamese government (project supported by Vietnam Ministry of Agriculture and Rural Development, 2016-2018, number: 04/TCTS-KHCN-HTQT-DT 2016).

\subsection{Statistical analysis}

IBM SPSS Statistics 20 software was used to analyze the data. Single factor ANOVA was applied to test for differences in the fish numbers in the Aeromonas-infected fishes receiving or not the phage therapy $(p<0.05)$. Standard deviations were calculated in all experiments.

\section{Conclusions}

The phages $\Phi 2$ and $\Phi 5$, belonging to the Myoviridae family, were successfully isolated and displayed inhibition of the growth of the A. hydrophila strains tested. The results obtained from the use of a phage cocktail indicate that phages can be used successfully for the treatment of Aeromonas infections in catfish via intraperitoneal injection. Phages may therefore be considered as potential biocontrol agents to combat Aeromonas infections in fish farms.

Supplementary Materials: The following are available online at www.mdpi.com/2079-6382/7/1/16/s1, Table S1: The $\mathrm{OD}_{550 \mathrm{~nm}}$ value of $A$. hydrophila N17 with the effect of Mitomycin C over the incubation time at $30{ }^{\circ} \mathrm{C}$; Table S2: Host range of the phages against Aeromonas species.

Acknowledgments: Authors would like to acknowledge the financial support from the Vietnam Ministry of Agriculture and Rural Development (2016-2018, number: 04/TCTS-KHCN-HTQT-DT). Son Le Tuan gratefully acknowledges MOET-VIED/USC PhD scholarship.

Author Contributions: Tuan Son Le analysed the data and drafted the manuscript. Thi Hien Nguyen, Hong Phuong Vo, Trong Tuan Tran, Hong Loc Nguyen, Van Cuong Doan, Minh Trung Tran and Tuan Son Le 
conducted the experiments under the guidance of Ipek Kurtböke, Thi Hien Nguyen, and Hong Phuong Vo, D. Ipek Kurtböke and Paul C. Southgate oversaw the preparation of the manuscript.

Conflicts of Interest: The authors declare no conflict of interest.

\section{References}

1. Nguyen, N. Improving Sustainability of Striped Catfish (Pangasianodon hypophthalmus) Farming in the Mekong Delta, Vietnam through Recirculation Technology. Ph.D. Thesis, Wageningen University, Wageningen, The Netherlands, 2016.

2. Dung, T.; Ngoc, N.; Thinh, N.; Thy, D.; Tuan, N.; Shinn, A.; Crumlish, M. Common diseases of pangasius catfish farmed in Viet Nam. GAA 2008, 11, 77-78.

3. Hien, N.T.; Lan, M.T.; Anh, P.V.N.; Phuong, V.H.; Loc, N.H.; Trong, C.Q.; Trung, C.T.; Phuoc, L.H. Report "Genetics of Aeromonas hydrophila on Catfish". Research Institute for Aquaculture No. 2. 2014. Available online: http:/ / www.sinhhoctomvang.vn/ban-tin/chi-tiet/Phat-hien-gen-gay-doc-cua-vi-khuanAeromonas-hydrophila-gay-benh-xuat-huyet-tren-ca-tra-106/ (accessed on 7 August 2017). (in Vietnamese).

4. Vivekanandhan, G.; Savithamani, K.; Hatha, A.; Lakshmanaperumalsamy, P. Antibiotic resistance of aeromonas hydrophila isolated from marketed fish and prawn of south India. Int. J. Food Microbiol. 2002, 76, 165-168. [CrossRef]

5. Guz, L.; Kozinska, A. Antibiotic susceptibility of Aeromonas hydrophila and A. sobria isolated from farmed carp (cyprinus carpio l.). Bull. Vet. Inst. Pulawy 2004, 48, 391-395.

6. Thi, Q.V.C.; Dung, T.T.; Hiep, D.P.H. The current status antimicrobial resistance in Edwardsiella ictaluri and Aeromonas hydrophila cause disease on the striped catfish farmed in the mekong delta. Cantho Univ. J. Sci. 2014, 2, 7-14. (In vietnamese)

7. Pridgeon, J.W.; Klesius, P.H. Major bacterial diseases in aquaculture and their vaccine development. CAB Rev. 2012, 7, 1-16. [CrossRef]

8. Hsu, C.-H.; Lo, C.-Y.; Liu, J.-K.; Lin, C.-S. Control of the eel (anguilla japonica) pathogens, Aeromonas hydrophila and Edwardsiella tarda, by bacteriophages. J. Fish. Soc. Taiwan 2000, 27, 21-31.

9. El-Araby, D.; El-Didamony, G.; Megahed, M. New approach to use phage therapy against Aeromonas hydrophila induced Motile Aeromonas Septicemia in nile tilapia. J. Mar. Sci. Res. Dev. 2016, 6. [CrossRef]

10. Ackermann, H.-W. 5500 phages examined in the electron microscope. Arch. Virol. 2007, 152, $227-243$. [CrossRef] [PubMed]

11. Haq, I.U.; Chaudhry, W.N.; Andleeb, S.; Qadri, I. Isolation and partial characterization of a virulent bacteriophage ihq1 specific for Aeromonas punctata from stream water. Microb. Ecol. 2012, 63, 954-963. [CrossRef] [PubMed]

12. Jun, J.W.; Kim, J.H.; Shin, S.P.; Han, J.E.; Chai, J.Y.; Park, S.C. Protective effects of the Aeromonas phages pah1-c and pah6-c against mass mortality of the cyprinid loach (misgurnus anguillicaudatus) caused by Aeromonas hydrophila. Aquaculture 2013, 416, 289-295. [CrossRef]

13. Kim, J.; Son, J.; Choi, Y.; Choresca, C.; Shin, S.; Han, J.; Jun, J.; Kang, D.; Oh, C.; Heo, S. Isolation and characterization of a lytic Myoviridae bacteriophage pas-1 with broad infectivity in Aeromonas salmonicida. Curr. Microbiol. 2012, 64, 418-426. [CrossRef] [PubMed]

14. Anand, T.; Vaid, R.K.; Bera, B.C.; Singh, J.; Barua, S.; Virmani, N.; Yadav, N.K.; Nagar, D.; Singh, R.K.; Tripathi, B. Isolation of a lytic bacteriophage against virulent Aeromonas hydrophila from an organized equine farm. J. Basic Microb. 2016, 56, 432-437. [CrossRef] [PubMed]

15. Chow, M.S.; Rouf, M. Isolation and partial characterization of two Aeromonas hydrophila bacteriophages. Appl. Environ. Microbiol. 1983, 45, 1670-1676. [PubMed]

16. Wu, J.-L.; Lin, H.-M.; Jan, L.; Hsu, Y.-L.; Chang, L.-H. Biological control of fish bacterial pathogen, Aeromonas hydrophila, by bacteriophage ah 1. Fish Pathol. 1981, 15, 271-276. [CrossRef]

17. Fortier, L.-C.; Moineau, S. Morphological and genetic diversity of temperate phages in clostridium difficile. Appl. Environ. Microbiol. 2007, 73, 7358-7366. [CrossRef] [PubMed]

18. Walakira, J.; Carrias, A.; Hossain, M.; Jones, E.; Terhune, J.; Liles, M. Identification and characterization of bacteriophages specific to the catfish pathogen, Edwardsiella ictaluri. J. Appl. Microbiol. 2008, 105, $2133-2142$. [CrossRef] [PubMed] 
19. CLSI. Performance standards for antimicrobial susceptibility testing 27th ed. CLSI supplement m100. Clinical and Laboratory Standards Institute. 2017. Available online: http:/ /www.facm.ucl.ac.be/intranet/CLSI/CLSI2017-M100-S27.pdf (accessed on 10 November 2017).

20. Lamy, B.; Laurent, F.; Kodjo, A.; Roger, F.; Jumas-Bilak, E.; Marchandin, H.; Group, C.S. Which antibiotics and breakpoints should be used for Aeromonas susceptibility testing? Considerations from a comparison of agar dilution and disk diffusion methods using Enterobacteriaceae breakpoints. Eur. J. Clin. Microbiol. Infect. Dis. 2012, 31, 2369-2377. [CrossRef] [PubMed]

21. Daka, D.; Yihdego, D. Antibiotic-resistance Staphylococcus aureus isolated from cow's milk in the hawassa area, south Ethiopia. Ann. Clin. Microbiol. Antimicrob. 2012, 11. [CrossRef] [PubMed]

22. Cerveny, K.E.; DePaola, A.; Duckworth, D.H.; Gulig, P.A. Phage therapy of local and systemic disease caused by Vibrio vulnificus in iron-dextran-treated mice. Infect. Immun. 2002, 70, 6251-6262. [CrossRef] [PubMed]

23. Le, T.S.; Southgate, P.C.; O'Connor, W.; Poole, S.; Kurtböke, D.I. Bacteriophages as biological control agents of enteric bacteria contaminating edible oysters. Curr. Microbiol. 2017. [CrossRef] [PubMed]

24. Paterson, W.; Douglas, R.; Grinyer, I.; McDermott, L. Isolation and preliminary characterization of some Aeromonas salmonicida bacteriophages. J. Fish. Board Canada 1969, 26, 629-632. [CrossRef]

25. Ackermann, H.-W.; Dauguet, C.; Paterson, W.; Popoff, M.; Rouf, M.; Vieu, J.-F. Aeromonas bacteriophages: Reexamination and classification. Ann. Inst. Pasteur Virol. 1985, 136, 175-199. [CrossRef]

26. Goodridge, L.; Gallaccio, A.; Griffiths, M.W. Morphological, host range, and genetic characterization of two coliphages. Appl. Environ. Microbiol. 2003, 69, 5364-5371. [CrossRef] [PubMed]

27. Phumkhachorn, P.; Rattanachaikunsopon, P. Isolation and partial characterization of a bacteriophage infecting the shrimp pathogen Vibrio harveyi. Afr. J. Microbiol. Res. 2010, 4, 1794-1800.

28. Hyman, P.; Abedon, S.T. Practical methods for determining phage growth parameters. Methods Mol. Boil. 2009, 501, 175-202.

(C) 2018 by the authors. Licensee MDPI, Basel, Switzerland. This article is an open access article distributed under the terms and conditions of the Creative Commons Attribution (CC BY) license (http:// creativecommons.org/licenses/by/4.0/). 